\title{
Learning preferences of clinical students: A study in a Malaysian medical college
}

Introduction: Awareness of learning preferences can have useful learning and teaching implications. However, there is paucity of literature on the learning preferences of clinical students in a medical school. This study uses the VARK questionnaire to explore the learning preferences of the clinical students of Melaka-Manipal Medical College, Malaysia. VARK is an acronym that stands for visual $[V]$, aural $[A]$, reading $[R]$ and kinesthetic $[K]$ sensory modality of learning. Materials and Methods: The study was approved by the College ethical committee. After taking an informed consent, the clinical students participated in the study in April/May 2012 [ $n=176]$. Instrument: VARK questionnaire Version 7.1 was used and it consisted of 16 multiple choice questions. It was distributed among students in the form of hard copy and they submitted their responses to the VARK questionnaire in a classroom setting. Statistical Analysis: Strong preference was calculated on Microsoft Excel using the VARK guidelines. Likert scale [1 to 5] was used to know their perceptions of their VARK score. Feedback written legibly by the participating students was included in the study [ $n=127]$. Results: The majority of students [ $n=99]$ were multimodal. Kinesthetic modality was the strongest single preference $[n=35]$. Out of 127 feedbacks included in the study, the majority of students [82.7\%] agreed with the validity of their VARK score. Conclusion: The majority of clinical students is multimodal in their learning preference and kinesthetic modality is their strongest single preference. Educational Implications: Students can develop learning strategies based on their preferences of learning. Teaching should involve all sensory modality so that all types of students can actively participate in learning session. Students pursuing clinical science can benefit more with the kinesthetic modality of learning.

Nirmal Kumar Sinha, Amit Bhardwaj, Simerjit Singh, Adinegara Lutfi Abas ${ }^{1}$

Departments of Orthopedics, and ${ }^{1}$ Community Medicine, Melaka-Manipal Medical College, Malaysia

Address for the Correspondence:

Dr. Nirmal Kumar Sinha, Department of Orthopedics, Melaka-Manipal Medical College, Malaysia.

E-mail: kumarnks@gmail.com

\begin{tabular}{|l|}
\hline Access this article online \\
\hline Website: www.ijmedph.org \\
\hline DOI: 10.4103/2230-8598.109325 \\
\hline Quick response code: \\
\hline
\end{tabular}

Key words: Clinical students, learning preferences, VARK test

\section{INTRODUCTION}

Learning of clinical science is a very challenging task in the life of a medical student. Clinical science requires practical integration and application of knowledge, skill and attitude learnt in medical schools in the environment of a hospital. The clinical students have dual responsibility of learning clinical examination, ward procedures, hospital practices and acquiring the theoretical knowledge of clinical subjects. Various strategies are being introduced and practiced in medical schools with the purpose of facilitating students to become better doctors. One of them is to identify the learning preferences of the students. Learning preference can be defined as the most effective and efficient modality or manner in which a learner has a natural preference to perceive, process, store and recall new information. ${ }^{[1]}$ Fleming and Baume ${ }^{[2]}$ see learning style as a description of a process or a preference. However, all of us have different psychosomatic traits. Each student has his or her 'own' learning preference. ${ }^{[3-5]}$ An inventory aimed to identify the way a student learns is 'a useful step towards understanding and hence improving learning?. ${ }^{[2]}$ Myers ${ }^{[6]}$ expressed similar thought when he said that 'understanding of the type [of learning] can make your perceptions clearer, your judgment sounder and your life closer to your heart's desire'. Many studies have been done to understand the learning preferences of medical students. Most of them are studies on non-clinical students or cross-sectional studies. However, there is paucity of literature on the learning preferences of clinical students. Hence, the present work was designed and conducted to provide information about it. We believe it would have useful teaching and learning implications for the students pursuing clinical education.

There are various approaches and inventories ${ }^{[2,6,7]}$ to identify the learning style of students, based on 
different psychosomatic behaviors of students. In the present study, we have used the VARK questionnaire developed by Neil Fleming ${ }^{[8]}$ to identify the learning preference of the students of our college. It is simple to use and easy to understand. VARK is an acronym that stands for the four major sensory modalities of learning: Visual [V], aural $[\mathrm{A}]$, reading/writing $[\mathrm{R}]$ and kinesthetic $[\mathrm{K}]$. Learning can be multi-modal. However, many learners have stronger preferences for one or more of these learning modalities. ${ }^{\left[{ }^{[9]}\right.}$ The awareness about the learning preference can empower students to modify their study methods and thus to optimize their performance in the examination. ${ }^{[10]}$

\section{OBJECTIVE}

The objective of the present study is to know the learning preferences of the clinical students in our college.

\section{MATERIALS AND METHODS}

\section{Population and sample}

Approval from the ethics committee of the college was taken to conduct this study in the Melaka-Manipal Medical College [MMMC], Malaysia. The college has an undergraduate medical course of five years' duration. Participants in this study consisted of students of two batches who had completed their basic sciences and were presently pursuing clinical courses. All the students present in the orthopedic classes on two separate days gave an informed written consent to participate in the project [ $n=176]$. The period of study was April/May 2012.

\section{Instrument}

The VARK inventory was used to sample sensory preferences of learning. VARK questionnaire Version 7.1 was used and it consisted of 16 multiple-choice questions. It was downloaded from the VARK home page available from http://www.vark-learn.com/english/ page.asp? $\mathrm{p}=$ questionnaire. Consent for download and the use for the project was taken from the developer of VARK. Students were briefed about the VARK questionnaire by one of the co-authors. The questionnaire was then distributed among students in the form of hard copy and they submitted their response to the VARK questionnaire at the end of their class.

\section{Definition of words used to describe various modal preferences of} learning:

Mono-modal: Having one of the V, A, R or K preference

Multimodal: Having more than one preference

Bimodal: Having two preferences

Tri-modal: Having three preferences

Quadri-modal: Having all the four preferences

\section{Statistical analysis}

The respondents summed up their respective VARK score in the classroom setting. The data was then entered in a Microsoft Excel sheet. Strong preference was calculated using the VARK guidelines. It is available from the site with url: http:/ / www.ntlf.com/html/lib/ suppmat/74vark2.htm. ${ }^{[11]}$

A five-point Likert scale was used to get the students' feedback about their perceptions of their VARK score. All the participating students gave the feedback, but only the feedbacks written legibly were included in the study [ $n=127]$.

\section{RESULTS}

The population studied in the project consisted of the students mainly from the multi-racial society of Malaysia. They comprised Malay [ $n=76]$, Chinese $[n=60]$, Indian $[n=34]$ students and six students formed the 'others' category. There were 121 female and 55 male students. Their age ranged from 21 to 25 years [average 23 years].

Calculation of learning preference showed that 77 students $[44 \%]$ were mono-modal and 99 students were multimodal [56\%]. The latter category comprises three subgroups, i.e., quadri-modal, tri-modal, and bimodal [Figure 1]. In the mono-modal category comprising 77 students, all the four preferences were represented and the kinesthetic modality was stronger than the others [Figure 2]. Complete breakdown of preferences showed that the kinesthetic preference was the strongest $[n=35]$. The next two strong preferences were aural and quadri-modal ones [Figure 3]. Validity of VARK test as perceived by the students was calculated using Likert scale. A total of 127 perceptions received from the students were included in the study. Half of them $[n=63]$ agreed with their VARK scores [Likert 4] and 42 students strongly agreed [Likert 5]. Twenty students were neutral and two students did not agree with the score [Likert 1 and 2] [Figure 4].

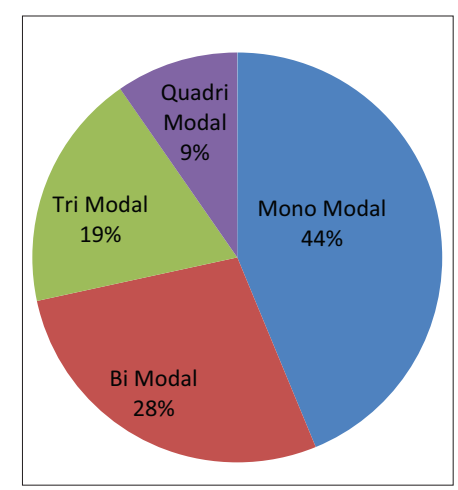

Figure 1: Preference percentage of one, two, three or four modes of learning of the medical students [ $n=176]$

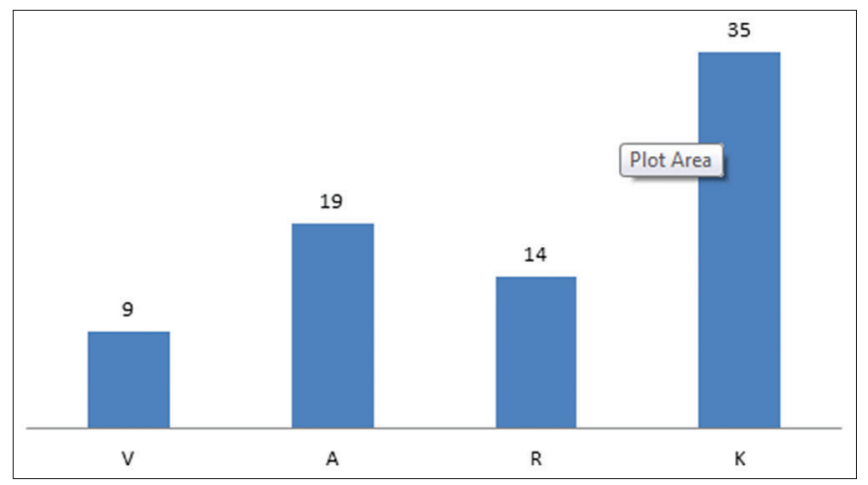

Figure 2: Bar chart showing breakup values of single preference in the mono-modal group [ $n=77]$ 


\section{DISCUSSION}

We found that the majority of clinical students [56\%] are multimodal in their learning preference [Figure 1]. In the multi-modal category, bi-modal was the largest one. However, the mono-modal category was larger than the other categories, i.e. bi-modal, tri-modal or quadri-modal ones. In the mono-modal category, kinesthetic preference [ $45 \%$ ] was the strongest one [Figure 2]. In fact, kinesthetic preference was the strongest of all preference[s] shown by the students [Figure 3]. The next two strong preferences were aural and quadri-modal types [Figure 3].

Many studies have been done to understand various sensory preferences of learning of students pursuing various disciplines. A study in 2004 on dental students ${ }^{[3]}$ showed that $56 \%$ dental students were multimodal. However, the single dominant preference in the mono-modal group was found to be visual. Analysis of first-year medical students in a US university ${ }^{[12]}$ showed that $64 \%$ of them were multimodal. In the same study the kinesthetic preference was 18\%. Another study of first-year medical students in a Turkish university ${ }^{[13]}$ showed that $63.9 \%$ students were multimodal and the kinesthetic preference was the biggest one $[23.3 \%]$ in the mono-modal category. A cross-sectional study ${ }^{[14]}$ of medical students of another Malaysian medical college done in 2009 indicated that $48.6 \%$ of undergraduate medical students were multimodal. The kinesthetic preference was the biggest one [35\%] amongst the mono-modal group, which is comparable to our results. A study amongst musical students of Thailand ${ }^{[15]}$ showed that

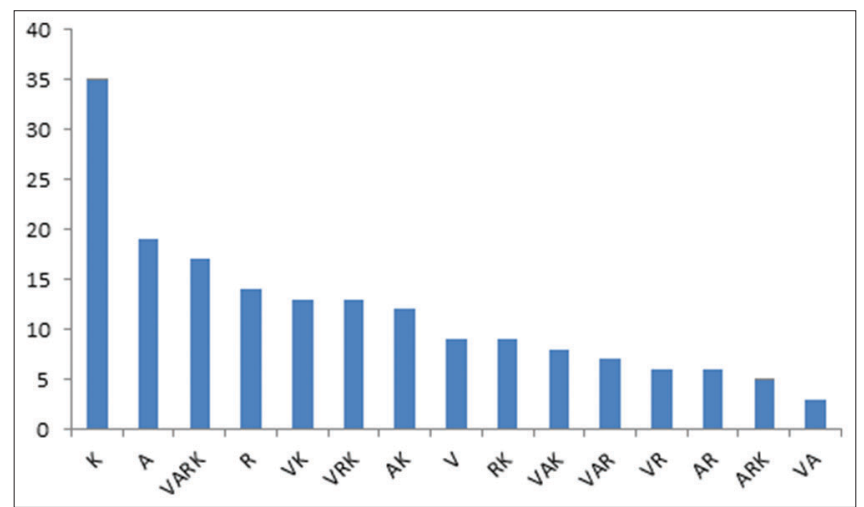

Figure 3: Students having mono-modal or multi-modal preferences in various combinations $[n=176]$

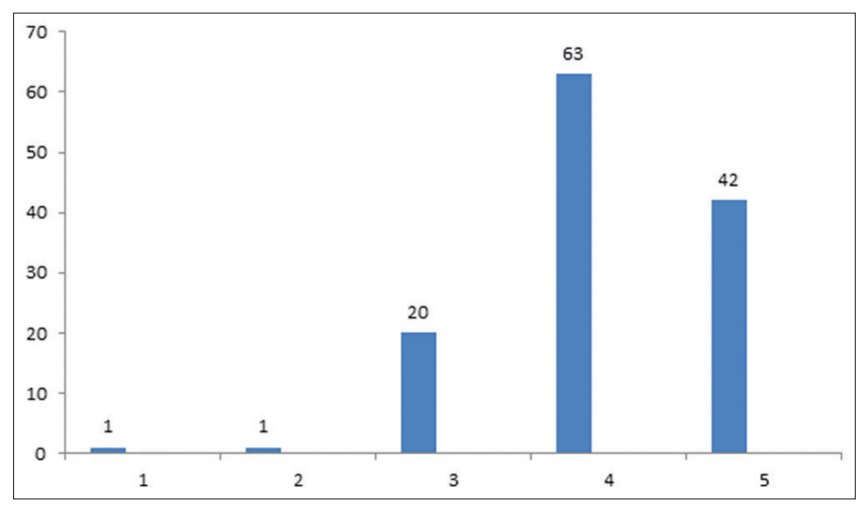

Figure 4: Students' perception of the validity of their VARK scores on Likert scale $[n=127]$
$66.1 \%$ were multimodal. Interestingly in this study, the aural group was the largest $[62.7 \%]$ in the individual group category. Another cross-sectional study of preclinical medical students in Saudi Arabia ${ }^{[16]}$ showed multimodality learning preference in $72.6 \%$. The same study showed the aural group as the largest in the mono-modal category. All these studies, like our work show that the majority of students are multimodal in learning. There are differences when the strongest single preference type is compared, as shown in various studies. The music students preferred aural modality. Aural preference was also shown by the preclinical medical students. This may be related to the fact that they have to attend many lecture classes. Our study included clinical students. In the last two years of undergraduate medical teaching, students have to learn clinical practices of hospital wards. This may explain their stronger preference for the kinesthetic modality.

\section{Implications for students}

Clinical students can develop strategies to study more in less time once they are aware of their learning preferences. As Fleming ${ }^{[10]}$ has observed, awareness about modal preference has in fact empowered students in his university to reflect upon sensory preferences and to modify their study methods accordingly. Students can select their particular preference(s) to understand how they should take in information, use it and communicate more effectively. ${ }^{[17]}$ The visual ones would learn most by visuals, flow charts, graphs, and underlining/highlighting using different colors. The aural ones would like to listen to lectures, discuss with peers, and attend conferences. They would benefit by using a voice recorder. The read/write ones would prefer handouts, class notes and textbooks. They would prefer to spend time in the library, rather than having a discussion session. The kinesthetic ones would like to attend workshops or hands-on seminars. They would like to spend more time in a skills' laboratory. They would learn better by simulation or demonstrations. They would like a case presentation more than a theoretical discussion. They would like to use all their senses - sight, touch, taste, smell, hearing, etc., to make learning sessions as 'life-like' as possible. The multiple preferences of multimodal students give choices of two or three or four modes to use for learning and for interaction with others. To enhance the learning experience, students can use strategies based on their preferences. ${ }^{[8]}$

\section{Implications for teachers}

All of us are multimodal and no student is restricted to one mode for intake. However, 'there are some dominant preferences [high score on a preference] and some voids [zero scores on a preference] among different students. ${ }^{[9]}$ Each student is different in his or her learning habit. Some are mono-modal while others are multimodal in various combinations. This awareness necessitates a change of teaching style. Teachers can improve their teaching module from a one-size-fits-all approach to a multimodal one so that all the students can benefit optimally. The teaching session would thus become more student-centric and less teacher-centric. The student would understand the topic better and thus become an active learner. In fact, while examining a relationship between preferred learning styles and course performance of physiology students, Dobson ${ }^{[18]}$ has found significant associations between preferred sensory modality and course scores. Knowing the students' preferred modes can: 1) help provide instructions tailored to the student's individual preference, 2) overcome the predisposition to 
treat all students in a similar way, and 3) motivate teachers to move from their preferred mode(s) to using others. ${ }^{[12]}$

\section{Implications for medical educators}

Medical science is expanding and so is the need to make changes in medical education. Information of different learning preferences necessitates a shift from the traditional large-class teacher-centric lectures to interactive, small-group student-centric classes. Teaching should involve all sensory modalities so that all types of students can actively participate in the learning session. Students pursuing clinical science may learn more with the kinesthetic sensory modality. Hence learning should be more in the form of ward experiences, skills' lab demonstrations and hands-on training in a workshop.

\section{Students' perception about the validity of the VARK test}

Students' perception about the validity of the VARK test was calculated using Likert scale. Half of them [49.6\%] agreed with it [Likert Scale 4] while 33.1\% strongly agreed [Likert Scale 5]. There was only one student each in the 'disagree' [Likert 2] and 'strongly disagree' [Likert 1] group while 20 students [15.7\%] were neutral in their opinion [Likert 3]. It can be concluded that a vast majority of the students $[82.7 \%]$ felt that the modality of learning preference as indicated by the VARK score was right for them.

\section{RECOMMENDATION}

Further studies-multi-centric and involving more number of students, are needed to assess a change in the learning habits of students and consequent improvement of their performance after they are made aware of their learning preferences.

\section{CONCLUSION}

The majority of clinical students are multimodal in their learning preference and the kinesthetic modality is their strongest single preference.

\section{REFERENCES}

1. Rourke BP, Ahmed SA, Collins DW, Hayman-Abello WE, Warriner BP. Child clinical/pediatric neuropsychology: Some recent advances. Clin Psychol 2002;53:309-39.

2. Fleming N, Baume D. Learning Style Again: VARKing up the right tree!. Available from: http://www.vark-learn.com/documents/educational\%20 developments.pdf [Last cited on 2012 Apr 20].

3. Murphy RJ, Gray SA, Straja SR, Bogert MC. Student learning preferences and teaching implications. J Dent Educ 2004;68:859-66.

4. Collins J. Education techniques for lifelong learning: Principles and adult learning. Radiographic 2004;24:1483-9.

5. The Nature of Preference. Available from: http://www.vark-learn.com/ documents/THE\%20NATURE\%200F\%20PREFERENCE.pdf [Last cited on 2012 Apr 20].

6. Myers IB. [homepage on the internet]. Available from: http://www. myersbriggs.org/ [Last cited on 2012 Jul 12].

7. Kolb AY, Kolb DA. The Kolb Learning Style Inventory-Version 3.1.[serial on the internet]. Available from: http://www.whitewater-rescue.com/ support/pagepics/lsitechmanual.pdf [Last cited on 2012 Jul 15].

8. Fleming N. VARK: A guide to learning styles. [home page on internet]. Available from: http://www.vark-learn.com/english/index.asp [Last cited on 2012 Apr 16]

9. Fleming ND. I'm different; not dumb. Modes of presentation (VARK) in the tertiary classroom. In: Zelmer A, editor. Vol. 18. Research and Development in Higher Education, Proceedings of the 1995 Annual Conference of the Higher Education and Research Development Society of Australasia (HERDSA), HERDSA, 1995. p. 308-13.

10. Fleming ND, Mills $C$. Not another inventory, rather a catalyst for reflection. To improve the Academy 1992;11:137-47. Available from: http://www. vark-learn.com/documents/not_another_inventory.pdf [Last cited on 2013 Jan 03].

11. VARK - Advice to Users of the Questionnaire[internet] Available from: http://www.ntlf.com/html/lib/suppmat/74vark2.htm [Last cited on 2012 Apr 19].

12. Lujan HL, DiCarlo SE. First-year medical students prefer multiple learning styles. Adv Physiol Educ 2006;30:13-6.

13. Baykan Z, Naçar M. Learning styles of first-year medical students attending Erciyes University in Kayseri, Turkey. Adv Physiol Educ 2007;31:158-60.

14. Kumar LR, Voralu K, Pani SP, Sethuraman KR. Predominant Learning styles adopted by AIMST University students in Malaysia. South East Asian Journal of Medical Education; 3[1]. Available from: http://seajme. md.chula.ac.th/articleVol3No1/OR6_Latha\%20Rajendra.pdf [Last cited on 2012 Jun17].

15. Tanwinit A, Sittiprapaporn W. Learning Styles of Undergraduate Musical Students Attending Music College in Thailand. Revista Electr. de LEEME (Lista Europea Electrónica de Música en la Educación).2010:25 [serial on internet] Available from: http://musica. rediris.es/leeme/revista/wichian10.pdf [Last cited on 2012 May 12].

16. Nuzhat A, Salem RO, Quadri MS, Al-Hamdan N. Learning style preferences of medical students: A single-institute experience from Saudi Arabia. Int J Med Educ 2011;2:70-3.

17. VARK-Study Strategies [SWOT] [homepage on internet]. Available from: http://www.ntlf.com/html/lib/suppmat/74vark4.htm. [Last cited on 2012 April 16].

18. Dobson JL. Learning style preferences and course performance in an undergraduate physiology class. Adv Physiol Educ 2009;33:308-14.

How to cite this article: Sinha NK, Bhardwaj A, Singh S, Abas AL. Learning preferences of clinical students: A study in a Malaysian medical college. Int J Med Public Health 2013;3:60-3.

Source of Support: Nil, Conflict of Interest: None declared. 